\title{
Technological change and the labour process - towards an analysis of computerisation in the New Zealand trading banks
}

\author{
John Brocklesby *
}

Within the labour process framework this paper examines the relationship between technological change and processes of control in the New Zealand trading banks. Adopting an historical perspective the author rejects a crude deskilling thesis but concludes that computerisation has served nevertheless to enhance management control. Moreover it is argued that recent changes in the climate of industrial relations in banking can only be understood within the context of changes in technology.

\section{Introduction}

In late November 1969 , the first stage in the computerisation of New Zealand banking ended, as the last remaining branch discarded its traditional processing methods and joined the Databank central processing system. Since then computerisation has gradually permeated nearly every aspect of banking. It has radically transformed the nature of work in the industry and will continue to do so in the future.

At the time of this first wave of computerisation, a characteristic feature of many writings on the topic was the emphasis placed upon the "emerging utopia" (Kumar, 1978) of automation. Typically it was argued that the new technologies would convey to workers increased control, would reduce levels of "alienation" and would lead to social integration within the enterprise (Blauner, 1964). Such a view is popular currency today. In contrast, Braverman (1974) considers this view to be naively optimistic. Instead of automation representing a qualitative change in technology, and for workers a change for the better, it is his belief that it is but a logical extension of previous forms of production. He contends that contemporary developments in technology not only serve to lower costs through dividing jobs and reducing skills, but also impose greater management control over the labour process by reducing the extent to which management has to rely upon potentially recalcitrant labour.

The central focus of Braverman's work is the deskilling of manual craft labour, but the "craft" form can also be applied to clerical work, ". . . although the tools of the craft only consisted of pen, ink, other desk appurtenances, and writing paper, envelopes and ledgers, it represented a total occupation." (Braverman, 1974, p. 298).

This analysis of technological change has gained considerable support. However, even the most ardent of Braverman's supporters have not accepted the deskilling thesis unconditionally, and in recent years there has developed a considerable literature which has sought to extend and refine his analysis of the labour process. This paper seeks to apply a number of themes in the post-Braverman debate, to an analysis of changes which have

* Lecturer, Department of Business Administration, Victoria University of Wellington. The author wishes to express his appreciation for the valuable comments from other symposium participants on earlier drafts of this paper. 
taken place in the New Zealand trading banks following computerisation of the system in 1969. The paper is based upon a continuing research project which began in 1983 . To date it has involved in-depth interviews with past and present staff from different levels in the hierarchy, trade union officials, technical experts, and others associated with the industry. Additional data have been obtained through observation and the analysis of archive material and union documents.

\section{Theoretical background}

One of the more important lines of enquiry which has been pursued in an attempt to move beyond Braverman, has been that of clarifying the objective basis of job skills, Littler (1982), for example, attempts such a clarification by drawing upon Friedman (1961), and Fox (1974).

In making a distinction between the specialist and the specialised (semi-skilled) worker, Friedman applies 2 objective criteria:

Firstly, the specialists' sphere of activity stems from a previous professional training, whereas the specialised worker has not received any general training such as would form a background explaining or illuminating his unit of work by connecting it with the whole process. Secondly, the specialist still has a recognised trade or profession, whilst the specialised worker does simple repetitive jobs which no longer form part of any basic trade. (Cited in Littler, p. 7).

Noting the incompleteness of Friedman's model, Fox proposes an alternative two dimensional model based upon discretionary content and task range. It is this model which Littler favours. However, in order to gain insight into some of the changes which have occurred in the banking labour process, each of the following independent dimensions will be applied (see figure 1).

Figure 1 Key objective dimensions of job content

High control Low control

1. Knowledge of the production process

General - Specific

2. Work procedures

Non-routine - Routine

3. Task range

Wide - Narrow

4. Discretionary content

High - Low

For Braverman the basis of craft control is to be found in the performance of a wide range of non-routine tasks, knowledge of the whole production process, and the exercise of considerable job autonomy. Equally, the process of deskilling in which a mass of easily replaced detail workers is created in the interests of establishing management control, may be conceptualised as a movement towards the opposite pole of each dimension. However, changes in the labour process - banking included - rarely conform to such a straightforward deskilling thesis. Thus, the purpose of making the conceptual distinctions outlined in Figure 1, is to provide an objective basis against which more complex and possibly contradictory developments may be understood.

A second line of enquiry has focussed upon mechanisms of control which emanate from the broader organisational context in which jobs are located. One such mechanism - the employment relationship - relates to the conditions surrounding the appointment, promotion, and dismissal of employees. As Littler notes, the most crucial dimension of the employment relationship is dependency (p. 44). The key to the relationship between 
dependency and control is that once employees accept that they are tied to a particular employer, they are more likely to accept company policies.

I have outlined here the theoretical framework which will be used to analyse changes in the banking labour process. This will be followed by an analysis of the collective employee response to these changes. In the meantime, it is appropriate to consider some of the technological changes. Because banking is a complex business, it is also necessary to have some understanding of how the industry operates.

\section{Technology and the trading banks}

Essentially the 4 trading banks which currently operate in New Zealand have 2 main tasks. those of providing a savings, investment, and loans service on customer accounts, and linking debtor and creditor through the money transfer system. These functions have remained basically the same over time, although internal processing has changed and will continue to change substantially.

The first (local) bank in New Zealand was opened in the Bay of Islands in 1840. Between this date and 1940, technological changes were slow and peripheral - the telephone, typewriter, and adding machine. But as Dawe (1980, p. 2-3 notes, "still banking was essentially the highstool, and the ledger, and the passbook." Hand posted ledgers and passbooks began to give way to electric machines around 1935. In turn these were superseded by electronic machines in the 1950 s. In essence these were sophisticated adding and typing machines which were used to prepare ledgers, statements, and so on. But because the cheque handling process remained largely a manual function, the banks were still labour intensive. Nevertheless the use of office machinery had permitted the handling of a much greater volume of work without corresponding increases in staffing levels.

This process was intensified by the application of computers which had a capacity to handle accurately large volumes of data at unprecedented speed. Table 1 considers trends in staff productivity before and after computerisation.

Table 1 Trading banks staff productivity 1957-1980

\begin{tabular}{lrrrrr}
\hline Year & Total Staff & \multicolumn{2}{c}{ Accounts } & \multicolumn{2}{c}{ Transactions } \\
\hline & & Total & $\begin{array}{c}\text { Per Staff } \\
\text { Member }\end{array}$ & Total & $\begin{array}{c}\text { Per Staff } \\
\text { Member }\end{array}$ \\
\hline 1958 & 7492 & 592300 & 79 & $94.4 \mathrm{~m}$ & 12600 \\
1962 & 8932 & 741700 & 83 & $127.6 \mathrm{~m}$ & 14285 \\
1968 & 10319 & 809000 & 78 & $145.5 \mathrm{~m}$ & 14100 \\
1973 & 11721 & 1074500 & 92 & $205.5 \mathrm{~m}$ & 17533 \\
1978 & 14417 & 1301500 & 90 & $278.3 \mathrm{~m}$ & 19304 \\
1979 & 14983 & 1371600 & 92 & $293.5 \mathrm{~m}$ & 19589 \\
& & & & &
\end{tabular}

Source: Dawe (1980)

Note: These figures probably understate increases in staff productivity. All Databank staff are included in the table, including those who provide services to non-banking clients. In addition this data only relates to traditional banking functions. No account is taken of the massive increase in the range of services provided since 1968 . 


\section{The Databank system}

In the mid 1960s the growth of cheque usage (see Table 1) was rapidly increasing the amount of paper work and having an adverse effect upon clerical labour costs. Increasingly the limitations of time-honoured but cumbersome manual and machine methods were becoming obvious. Prompted also by the additional burdens of decimalisation and the introduction of savings bank facilities, and in the face of recruitment problems generated by post war affluence, a reform of banking procedures began with the computerisation and centralisation of customer and financial account records. The BNZ opened two computer centres in 1966 . The other banks joined the system in 1967, and a nationwide coverage was fully operational by the end of 1969 . Owned by the member banks, the new system was set up as a separate organisation called Databank Systems Ltd.

The Databank system requires that documents such as cheques are pre-encoded with the customer's account number, bank branch and so on. To this, additional information is manually encoded on vouchers before being couriered to the Company's network centres. It is then transferred on a telecommunications link to the central processing centre. Overnight the data is processed automatically, and the following morning a report is produced which details the net flow of capital between each bank. At the same time the system performs traditional ledger functions; calculating interest and charges, as well as providing management with information on customers, accounts, personnel, and so on.

Approximately 95 percent of branch input into the system takes the form of encoded cheques or other documents, all of which rely upon manual labour in one form or another. Increasingly however, there are a number of money transfer services which bypass this relatively expensive part of the process. These include automatic payments of regular transfers between 2 accounts, direct debits, and direct credits. More recent services of this type which are available through Databank include those provided by the Society for Worldwide Interbank Telecommunications, automatic teller machines, and direct transaction capture (hereafter SWIFT, ATMs, and DTC).

Introduced in 1982, SWIFT provides its member banks with an international transaction route which allows direct dealing from New Zealand to a wide range of destinations via a central processing centre located in Sydney. This allows for the rapid transfer of funds from one country to another without the need for the transfer of paper, and with a vast reduction in the number of transactions and staff involved.

Today ATMs are a well known feature of the banking scene. They are operated by customers and provide a direct link to the computer which enables the customer to accept deposits, make payments, transfer money between accounts, and handle enquiries. In doing so they bypass the bank teller.

By the end of 1982 most branches had installed direct terminal access to the computer's customer information files, thereby providing staff and customers with an instantaneous account information service. At this stage these terminals merely provided a file "viewing" and "maintenance" function, but in an attempt to reduce the amount of paper moving between its' branches and Databank, the ANZ began an experiment with terminals which would enable tellers to automatically process transactions directly with the computer files. Basically this system allows tellers to record most transaction details directly into the terminal, thus eliminating the processing and movement of money vouchers and other paper work. Additionally it provides automatic branch cash control and credit card authorisation functions, and the programmed terminals have the capacity to approve or reject loan requests. Should this system become widespread it would involve a significant reduction in services provided by other staff or other departments, towards one in which most branch work is handled by front line tellers. For this reason some technical experts consider DTC to be one of the most important developments in New Zealand banking since the creation of the Databank system (Chequemate, 30 March 1982).

Further money transfer services which will supplant many cheques and other paper transactions, and which have enormous labour saving potential, will be introduced in the 
immediate future. Management at Databank has estimated that by 1986, about 70 percent of all transactions could be by the electronic transfer of funds, and senior management in the industry has made clear its commitment to this form of development.

All parties are generally agreed that continued rapid progress toward all electronic transactions generated from plastic cards as a substitute for paper based transactions is a desirable goal. (Hogg, 1981, p. 221).

The most recent innovations of this type have been point-of-sale terminals and home banking. Point-of-sale terminals enable retailers to deduct automatically the amount of the bill from the customer's debit account, and add it to their own account, and home banking provides the opportunity for customers to request statements, transfer funds, and pay bills electronically using a keyboard linked to the television.

Many of these innovations are already operational. However, the $\$ 30 \mathrm{~m}$ computer package order which Databank placed with IBM in 1983 - at the time the largest single computer order ever announced in New Zealand - and a recent estimate that the local market will absorb 40000 point-of-sale units by 1988 (The Dominion, 12 November 1984) bears testimony to the scale of imminent changes in the industry.

\section{In-house computerisation}

In addition to the Databank central computer facility, the banks have developed extensive computer networks themselves. This has led to a centralisation of many traditional and new functions, mainly because the traditional decentralised branch structure is unsuited to the efficient deployment of expensive mainframe computers. The centralisation of traditional functions has come about with the creation of area and regional offices.

The area banking concept is that an area office provides some technical support services for individual branches, but at the same time removes functions which were previously carried out by the branch. For example, the operation of this system in one of New Zealand's Australian owned banks has led to the centralisation of cheque proofing, lending, and international work.

At the BNZ a similar innovation began in 1968 with the creation of an International Business Division. This was followed by district offices covering the main centres in 1973. In 1981 a Business Division handling small businesses, farming and professional customers, and a Corporate Banking Division responsible for major business customers were established. And finally the Bank opened 3 area offices, iricluding international centres, in 1983.

In the mid 1970 s the centralisation of traditional functions was reinforced by the additional centralisation of new services such as travel and credit card facilities. The BNZ Visa service was first offered to customers in 1978, and by 1980 all administration and processing of transactions was handled by a major computer installation at the Bank's head office.

\section{The banking labour process}

\section{Traditional banking}

\section{(1) Job content}

In some respects traditional banking epitomises that of the craft tradition. Witness the following descriptions of the banker's role.

His duties require that he have a good knowledge of values of land, stocks, shares, etc... of accountancy and law, including that concerning local bodies, companies, partnerships, 
trustees, bills of exchange, bills of sale, and .... a still better knowledge of human nature. Firmness, tact, courtesy, and a desire to be of service both to his bank and to its' customers are also requisite to his success. He must be neither an optimist nor a pessimist, for an optimist lends too frequently, and a pessimist hesitates to lend at all . . . he must keep in touch with the affairs of his community and of his country and with world movements generally, especially in so far as they affect finance and trade. (Moore and Barton, 1935 , p. 256)

and

Banking was pre-eminently a profession, and was so regarded ... the banker is still ... master of his own house. In fact he remains the most skilled purveyor of credit in the community. It is a life-long study. The ability to guage the difference between a satisfactory and an unsatisfactory banking proposition is achieved only after a long apprenticeship. No officer of less than 20 or 25 years experience would be sufficiently qualified to authorise the granting of advances. (Chappell, 1961, p. 380).

These descriptions of traditional banking reflect upon the 4 dimensions of "craft" control - the performance of a wide range of non-routine tasks, knowledge and control over the whole production process (at no stage was control over data relinquished), and the exercise of considerable autonomy. Of course not every recruit would eventually become a branch manager. However, a shortage of suitable labour and consistent growth in the industry provided many opportunities to those who were able to demonstrate their worth.

Moreover, a number of writers have alluded to a "golden age" of "craft" control, in which considerable initiative was required even of the lower status clerk (Stickler, 1949, p. 24). Equally one needs to emphasise the clerk's knowledge of the whole production process (there is little evidence to suggest that a systematic division of labour developed in the industry until the First World War, and in the smaller branches it remained undeveloped after this date), and the opportunity for staff to influence internal organisation and work procedures. When this issue was raised with (now retired) branch managers, several commented on the fact that even in the immediate pre-computerisation period, branch autonomy enabled different recording and processing systems to be used from one branch to another.

On the other hand the "craft" nature of branch management should not be adopted as a benchmark against which more recent changes are measured, without some degree of qualification. Twenty-five years is a long apprenticeship, and it is in analysing the content of some lower status positions that the suitability of this benchmark becomes more open to doubt. For example, Stickler observed that by 1949 ,

the duties of a bank (have) been so reduced to routine that the difficulty is to find work which calls for intelligence in sufficient quantity to keep engaged those members of the office staff who have demonstrated their ability to perform such work ... many men feel that the vast majority of the tasks that they do for the first 25 years of their service are numbingly monotonous. (1949, p. 25).

Neither should the discretionary content of lower level work be overemphasised. Especially in the main centres, the inter-war period saw an increase in the size of many branches and this necessitated a more clearly defined division of labour. In turn staff became subject to the dictates of bureaucratic procedures, for example, written job descriptions and branch manuals, and frequently their duties were prescribed in some detail. Although these written guidelines were always subject to different interpretations and could not rule out discretion entirely, clearly this is not a characteristic feature of a "total occupation". In considering the changes arising from the computerisation of the industry a major issue is the extent to which the new systems have reversed or extended this trend.

\section{(2) The employment relationship}

Traditionally banking held out the possibility of upward mobility through a permeable hierarchy into the ranks of a secure middle class position. The vast majority of staff were recruited directly from school, thus creating a broad organisational base from which future 
promotions could be made. Hence a key feature of the employment relationship was that staff were not hired for a particular position, but with every expectation that they would eventually achieve executive status. As a result most managers had worked their way up through the system. Accordingly, ". . . it is very true that in banking every private carries a field marshal's baton in his knapsack." (Stickler, 1949, p. 27).

On the question of promotions the practice was not for individuals to apply. Rather the burden was placed upon staff to demonstrate their ability and motivation by passing the Institute's examinations, obtaining favourable annual reports from the branch manager, and gaining all-round experience by accepting regular job transfers. Training, which was mainly carried out on the job, was controlled by the manager or accountant who would take note of workflow requirements, as well as the needs of staff to gain experience in a wide range of branch activities. Incremental salaries, based upon an 18 year scale, were further indicative of the perceived value of accumulated experience and continual learning.

While ostensibly benefitting staff, this highly bureaucratic career structure confers upon management a number of strategic benefits. Of particular importance is the structured dependency upon the bank which the system entails. The expectation of lifetime employment coupled with a policy of internal promotions, with little advertising of vacancies, and next to no inter-bank mobility, creates an employment relationship of commitment and dependency. This was reinforced by housing loans at favourable rates of interest and pension schemes. Consequently staff were provided with a strong inducement to perform as management desired. Any withdrawal of cooperation and goodwill would have a potentially serious impact upon future careers. The effect is such that the banking employment relationship offers considerable potential as a mechanism of control.

On the other hand, as recent research in Australia suggests (Game and Pringle, 1983) this scenario tells only half of the story. The exchange of dependency and subordination in the labour process in return for career security and advancement, was as much a feature of the banking employment relationship in New Zealand as in Australia. But in both countries, it applied only to men.

The first female staff were employed by the BNZ in 1915 so as to release male staff who were volunteering for military service. A steady increase in the numbers employed peaked in 1918, by which time nearly a third of the total staff compliment of 1000 were females. After the war most resigned, although a small number of single women did stay on to perform routine clerical, secretarial, and typing duties. During the Second World War women were again employed in large numbers. In 1943, of approximately 2000 staff, 713 were females. Typically it was still a case of the women "assisting the men". Exceptionally however, the shortage of skilled labour meant that the few experienced women in the industry were required to carry out tasks of some responsibility. (In one interview, a woman whose service began in 1920 pointed out that she had been instructed to set about redesigning her bank's share register during the war). After the war the numbers were reduced by about a half, partly due to the return of the men, and partly due to other employment opportunities. This situation changed in the early 1950 s as women entered the industry in larger numbers in response to the need to cope with labour shortages and the increased volume of work caused by economic growth.

Wearing uniforms, often physically separated from career staff and customers, excluded from the career grades, and paid lower salaries, most of the women were employed purely as machine operators or as "non scale officers" engaged in routine tasks of form filling and data preparation. Prospects for advancement were limited to the supervision of other women and office juniors. Significantly before the advent of ledger machines in the industry, ledger keeping was not a junior position. Typically a male clerk would require up to 5 years experience before he could expect to advance to ledger keeping duties. After mechanisation women were carrying out the same functions almost immediately, and in terms of the dimensions outlined earlier they were occupying ideal-typical low control roles. Frequently women were seen as being more suited to this type of work. One ex-manager recalled a widespread reluctance on the part of male staff to operate the 
machines, and one woman recalled a male colleague actually resigning his position as a protest against the number of females being engaged. Another ex-manager suggested that the disproportionate number of female machine operators could be explained through reference to their "nimble fingers" which made them ideally suited to such work. Not having to present any ideological justification for this inequality enables Stickler to offer a more valid explanation,

Here modern methods with mechanisation are to help since the supply of female clerks ... can cope with a great deal of the simplest and most monotonous work of an office (1949, p. 27).

Thus the emerging pattern was one in which the introduction of new technologies coincided both with a redistribution of tasks among low control labour, and a feminisation of the industry.

In the immediate pre-computerisation period women gradually became involved in most lower level branch activities. But despite a severe shortage of suitable labour, their role in the industry remained one of marginal importance. In the 1965 annual report, the Chairman of BNZ commented that, "(in order) to provide for continued growth ... it will be necessary to continue the drive for male recruits of good calibre." By implication women were not seen as suitable career material at this stage.

\section{Computerised banking}

Before turning to a consideration of the new labour process, it is important to make a key distinction between computerisation and earlier forms of technological change. The basis for this distinction is that computerisation did not simply provide a means of technically improving existing methods, for example in the same way in which ledger machines improved earlier hand posted methods. In addition, computerisation facilitated a significant restructuring of the industry away from the traditional branch and head office system. At the time of the change the effect upon banking employment was significant, but it is only in recent years that the full ramifications of computerisation are being understood.

Unfortunately the magnitude of this change creates a number of difficulties for anyone attempting to analyse its impact in terms of job content and employment relationships. Not least is the fact that some jobs have disappeared whilst other new jobs have been created. Some have been dismantled and reconstructed in a different form elsewhere, new labour processes having been created in the process. This necessitates a consideration of jobs which are no longer located within the branch structure, but are to be found, for example, in the central processing centres and area offices. Of course computerisation has also radically altered the content of many jobs which otherwise have remained intact within the branches.

The picture is further complicated by other changes which have parallelled computerisation. For example, an increase in the range of services provided by the banks, and a major staff regrading exercise which took place in 1974. The reluctance of the banks to provide data, in particular that pertaining to the numbers of staff carrying out particular duties, creates further difficulties. Accordingly, the analysis which follows offers no more than a general picture of the computerised labour process.

(1) Job content

(a) Centralised data processing

After computerisation, many branch processing, recording, and checking tasks which were carried out originally by career-oriented males, but more recently by females, have 
been incorporated into the work handled by Databank. Also noted earlier was the centralisation of new processing functions into area offices, Visa centres, and so on. What is work like for data processing staff who are employed in these centres?

Discussions with computer centre staff and published material (for example, Databank Systems Limited, 1982, p. 10-11) give the impression that the most important feature of this work is the intensified division of labour and fragmentation of tasks which has developed under assembly line-type conditions. Positions which characteristically exercise low control, according to each of the 4 dimensions, are common. The jobs of courier, input and output clerk, reader/sorter operator, and reconciliation clerk all fall into this category. Much of the information necessary for the satisfactory performance of cheque clearing and money transfer tasks is contained in the computer, and there are few decision-making or coordination tasks which require the intervention of staff. Even in higher graded positions the task of operations staff has become one of ensuring that the system processes the data according to pre-determined schedules. Mainly staff feed data into the computer and then act on its' instructions. Most of the operations staff require very little knowledge of the functions carried out by the computer, let alone of the banking industry itself.

Elsewhere the credit card centres and area offices are organised along similar lines. For example, work in the international section of an area office has been described as follows:

In short it is like working in a paper factory. There is extensive specialisation of tasks. Paper once it is generated by a customer or staff member, is passed between the desks and then it moves on. Staff perform a narrow range of tasks under constant pressure determined by external factors. (Goulter and McCall, 1981, p. 2).

Goulter and McCall note that job rotation is practised in some offices to mitigate some of the worst effects of the system $(1981$, p. 3). This was confirmed in discussions with area office staff. The sorting of agents' bills alphabetically by name of customer from As to $\mathrm{Ms}$ in the morning followed by Ns to $\mathrm{Zs}$ in the afternoon, was given as an example of this practice.

Whilst much of the work which was once carried out in the branches, and for which it was considered necessary to employ upward aspiring male clerks, has been eliminated by computerisation, the remainder is now performed by a stratum of easily replaced low control workers. At the same time the new systems have created a need for a much smaller number of high status specialists. By and large this group of staff is also located away from the branches.

\section{(b) Specialist functions}

Undoubtedly the technology used in banking today has created a need for some highly qualified computer and systems staff, and the centralisation of other banking services has created a similar need in other specialist fields. Whilst obviously few in number, it has not been possible to ascertain the exact number of these experts, or how many branch positions they have displaced. Nevertheless, one useful indication is the estimate that for every 3 grade $3 / 4$ international positions lost in the branches, only 1 is picked up in the area offices (Goulter and McCall, 1981, p. 3).

On the question of control, the key issue is knowledge of the production process. Because of their specialised duties and responsibilities these staff can become isolated from wider banking activities. When interviewed several complained that the system can act to the detriment of their careers, mainly because promotion to senior positions still requires all-round experience. As an example, under the traditional branch structure relatively senior staff would expect to carry out international functions for a maximum of 3 or 4 years. Today under centralised structures 10 years service is common. In one bank, formal training courses for branch staff used to cover the whole range of international functions. Today they have been replaced by much more specialised on the job training. 
Moreover, area office staff are denied the opportunity of broadening their experience by filling in for vacationing or sick colleagues who are employed in other branch activities. This was the practice by which international staff were able to gain experience of lending functions, thereby increasing their chances of promotion.

Notwithstanding this point, the content of some of these positions, coupled with a level of knowledge and expertise which is frequently hard to find, can confer upon the experts a significant degree of control. This is certainly true of those computer staff who are involved in systems design, and it has already resulted in the payment of industry equivalent salaries to these people. Doubtless senior management is aware of this problem. As Boswell notes,

In all industries.... there is a determined effort to get rid of expensive people whose jobs can be automated and to replace them with relevant activities being performed by machinery" (The Press, 30 August 1983).

Perhaps the interest which the banks have been showing in sophisticated software packages developed outside the industry, signifies the beginning of a reduction in the control wielded by their own technical experts.

\section{(c) The branches}

As union commentators have observed, the most noticeable physical difference in branch activity was the removal of conventional ledger machines, and with it the removal of ledger keeping, adding, balancing, interest calculations, and similar jobs associated with the processing of vouchers under the old system (All Union Conference on New Technology, 1981). Many checking, coordinating, and supervisory functions were also to disappear, although some checking was to remain as a post processing operation. In their place there is now a new breed of batching clerks, input clerks, and in most branches, proof machinists. Graded at the bottom of the hierarchy this type of work is repetitive, routine, and it offers little scope for the use of discretion or gaining insight into other branch activities.

The loss of some middle level functions and the creation of this category of work provides a highly visible reminder of how computerisation has altered the shape of branch banking. Beyond this, an explosion in the banks' range of services has served to conceal the impact upon other more central areas of branch activity. Not only have the new services increased the branch division of labour, as new positions such as travel and customer services officers have been created, but it has also meant an increase in the task range for some of those carrying out.more traditional functions. The work of tellers provides a useful illustration.

Nowadays, although tellers no longer possess any detailed knowledge of banking processess, they do handle a much wider range of transactions, and especially in the smaller branches where they are the first point of customer contact, they are required to have some knowledge of most banking services in order to answer questions and market the bank's services. Along with other staff they are constantly having to learn new procedures, and ostensibly they are required to make many "decisions" in performing their work. This has drawn some staff and their representatives to the conclusion that today banking makes greater demands upon staff than previously.

However, on closer examination it is clear that many of these new activities mainly require the application of standardised regulations and procedures, sometimes to the extent that an increase in task range is offset by a lack of discretion. In essence one of the most important ways in which computerisation extends management control is by promoting bureaucratic rationality in decision making. Basically this involves lower level staff making decisions, but only according to principles elaborated by senior management (for a discussion on this, see Crompton, 1981, p. 424). This form of low control "decision making" is becoming increasingly common in all areas and at all levels in the industry, but it is 
most noticeable in the work of those who operate direct input terminals. Not only do these machines have the capacity to process transactions through their direct link with the computer, but they can also apply standard procedures which effectively remove decision making functions from either the operator or the more senior officer who previously would have used background knowledge and experience to arrive at an appropriate decision.

A past president of the New Zealand Bank Officers Union (NZBOU) has outlined a practical application of this process:

... if I had wanted a loan from the bank, an employee at one of the terminals would simply punch in the details of my requirement. Up on the VDU screen would appear a list of questions which I would have to answer. As I answered the questions the bank employee would punch the details into the terminal and at the conclusion of which the computer would either grant or decline the loan ... If I wanted to make a remittance to London.... any one of the counter staff could have done it by simply punching the details into the computer . . . the money would have been in London within minutes. (Pilling, 1982).

Given the nature of these changes, it is hardly surprising that telling is no longer the prestigious job it once was. Traditionally advancement to telling duties would have take at least 4 or 5 years, but, as several ex-managers pointed out, the average branch experience of newly promoted tellers would have been closer to 10 years. Nowadays telling is a grade 2 position which can be reached after 6 months service. It is often performed by parttimers.

Attention has already been drawn to the loss of specialist functions to central offices, and the loss of supervisory roles and "middle level" discretion to the computer. But it would not be appropriate to conclude a discussion of the new branch labour process without mentioning the work of branch managers. Generally most of what has been said to this point applies equally to mangers. The loss of processing functions to the computer means that branch performance can no longer be explained as a result of branch efficiency, or the calibre of staff. Databank requirements and deadlines impact upon internal branch organisation, and the whole processing function has been standardised. Databank carries out many personnel functions, and marketing compaigns are established by head office. No longer can it be said that managers are the masters of their own house. In a sense their control is being eroded from 2 directions. At one end, business which departs from routine is often referred to the specialists, and at the other end routine decisions are being handled by the computer.

\section{(2) The employment relationship}

Prior to computerisation, the dual nature of employment in the industry was noted. Male clerks were locked into a relationship of structured dependency which was built upon a system of upward mobility reinforced by the absence of any external banking labour market. Females were confined to secondary positions. To what extent has computerisation altered this picture?

Undoubtedly the single most important change has been a reduction in the extent to which the hierarchy provides an avenue of upward mobility for lower level male staff. Today it is clear that many of the newly created specialist positions do not represent an avenue of opportunity for mainstream branch staff, even less for the mainly female data processing staff, some of whom are located outside the bank career structure. The ability of the computer to eliminate intermediate functions which used to be carried out by senior clerks further reduces the opportunities for advancement.

Changes in recruitment policies have paralled these changes in employment relationship. Increasingly selective entrance requirements based upon educational attainment, and the creation of "fast track" career structures for graduates, will make it progressively more difficult for the average recruit to achieve executive status. With increasing specialisation there has been a movement away from what Game and Pringle (1983) call the "grow 
your own" policy. Thus the trend in respect of computer work has been to recruit specialists from outside the industry, sometimes from overseas, and to recruit graduates in their mid 20s specifically for programming, on the basis of aptitude tests. However, horizontal recruitment is not restricted to the computer field. In recent years the banks have looked outside the industry for money market experts, corporate analysts, foreign exchange dealers, research economists, travel consultants and so on. And despite claims that all new entrants have the same opportunities to advance in the industry, it is clear that targetted positions do not offer prospects for advancement. In a written directive to its recruitment personnel, Westpac management identified keyboard operators, part-time tellers, and enquiry clerks, as examples of "non career" duties. A complaint brought by the NZBOU, and upheld by the Human Rights Commission, was based not so much upon the fact that such duties existed, but because the directive required that they be carried out by females.

Overall the picture is one in which a traditionally multi-layered and permeable hierarchy has been replaced by one in which occupational boundaries have become more rigid, with the gap between hierarchical levels widened. Accordingly the employment relationship, in itself, is less reliable as a mechanism of control.

For a small number of females in the industry the position has been reversed. During the 1970 s, legislation guaranteeing formal equality in the workplace forced the banks to slowly open up career structures to women. Since then some women have advanced to executive positions. But as Table 2 demonstrates the industry is still highly segmented along gender lines. Overwhelmingly females remain concentrated in the so called "pink collar" sector where they are overrepresented amongst those engaged in data preparation, routine clerical, machine operating, and telling positions. Notwithstanding the banks' stated commitment to provide more opportunities for females, it is patently obvious that computerisation has not significantly altered the 2 tier structure of employment which existed before 1968 .

Table 2 Staff numbers by grade and sex in the four trading banks in New Zealand

\begin{tabular}{lcccccc}
\hline & \multicolumn{3}{c}{1979} & \multicolumn{2}{c}{1981} & \multicolumn{2}{c}{1983} \\
\hline & $\begin{array}{c}\text { Male } \\
\%\end{array}$ & $\begin{array}{c}\text { Female } \\
\%\end{array}$ & $\begin{array}{c}\text { Male } \\
\%\end{array}$ & $\begin{array}{c}\text { Female } \\
\%\end{array}$ & $\begin{array}{c}\text { Male } \\
\%\end{array}$ & $\begin{array}{c}\text { Female } \\
\%\end{array}$ \\
\hline Grade 1 & 8.1 & 14.9 & 7.4 & 12.8 & 4.6 & 7.1 \\
Grade 2 & 24.0 & 64.2 & 25.6 & 62.9 & 26.3 & 62.7 \\
Grade 3 & 19.2 & 18.7 & 18.6 & 20.9 & 18.6 & 24.8 \\
Grade 4 & 10.8 & 1.8 & 10.0 & 2.8 & 10.8 & 4.3 \\
Grade 5 & 4.4 & 0.2 & 4.4 & 0.3 & 4.9 & 0.4 \\
Accountants & 13.3 & 0.2 & 13.6 & 0.3 & 13.9 & 0.6 \\
Managers & 20.2 & - & 20.4 & - & 20.9 & 0.1 \\
\hline \% & 100 & 100 & 100 & 100 & 100 & 100 \\
TOTAL & 6284 & 6605 & 6624 & 7313 & 6836 & 7514 \\
No. & & & & & &
\end{tabular}

Source: The Bankers Association. Examples of positions under the various grades are as follows. Note: Typists, telephones, telex operators, receptionists, messengers, drivers, etc. not included.

Grade 1:

Grade 2:

Grade 3:

Grade 4:

Grade 5: batch clerk, input clerk, mail clerk, proof machinist. teller, bills clerk, micr controller, voucher examiner. import/export clerk, head teller, term deposits clerk, senior bills clerk. no. 1 bills, no. 1 advances, head ledger keeper. head advances, head bills, head securities. 


\section{Collective responses to computerisation}

Not surprisingly the banks have sought to create a climate which is conducive to change by consistently pointing to the increased responsibility and challenge which staff could expect from the new systems (for example see BNZ Annual Report 1967, p. 28). This kind of strategy is often successful, but it does run the risk of provoking a reaction from staff who believe that additional skills and responsibilities, if they exist, should be paid for.

In 1981 the NZBOU included in its award claim an additional 6 percent as a special increase for all staff as recompense for added skills and responsibilities caused by new systems and new services. The claim was declined by the banks following which staff voted overwhelmingly in favour of industrial action. This took the form of a 1 day strike followed by rolling stoppages. As a result of this action a special committee comprising union and management representatives was set up to examine the whole issue of increased skills and responsibilities. In August the committee identified areas of change and resultant increases in skill. As expected the union focussed upon the need for its members to be familiar with a wider range of services, to market these services, the need to learn new procedures and to develop new skills, particularly those involved in the operation of keyboards. The implication is that there has been an upgrading of skills simply as a result of the need to learn techniques. No apparent attempt was made to clarify the objective basis of the new tasks, neither was reference made to any loss of skills, or overall reduction in the discretionary content of work. In fairness to the union its case was also based upon increases in staff productivity.

Somewhat ironically, whilst acknowledging that a case could be made for a small increase in salary ( 2.5 percent was the final offer) for grades 3,4 , and 5 , the employers rejected the remainder of the union's claim for lower graded staff on the grounds that much work had either been simplified or subject to standardisation procedures (NZBOU Report for members, 1981). The significance of this should not be lost, because in 1981 55 percent of all staff, and 76 percent of females were employed in these grades (see Table 2). On the basis of their own evidence it would seem that the banks were not entirely justified in their claim that staff could expect more challenging work as a result of the new systems. In November the claim was referred to the Arbitration Court, and in a compromise move it ruled marginally in favour of the union.

In the meantime technology committees had been established in each of the banks, and the union had come up with an initiative which recommended negotiations over the conditions surrounding the introduction and operation of equipment concerned with the new services. As a result of the banks failure to accede to this request, the union proposed a banning of the machinery - a move hitherto unprecedented in the industry - at which time the staff concerned would have the opportunity to vote on whether the ban should remain in force. A clear majority of staff endorsed this initiative, and the banks were formally requested to enter into negotiations concerning any major changes of systems or services. The banks' response was ambivalent. On the one hand, taking a narrow view of the committees' functions, they agreed to communicate with technology representatives. But in emphasising their traditional prerogative to introduce new systems on a unilateral basis, they rejected outright the request for negotiations.

In June 1982 the union came up with a further initiative. Following its successful introduction in the Commonwealth Bank of Australia, the union put forward the case for 1 rostered day off per month for each of its members in return for the introduction "... on an agreed basis and within certain limits ..." (Chequemate, July 1982), ATMs, SWIFT, DTC, and other new systems. Even before the claim was formally lodged it was rejected, despite the fact that the banks were each operating similar schemes for their staff in Australia. Before the issue could develop any further, the Government introduced the wage freeze and this prevented the banks from granting reduced working hours, even had they wished to do so. 
It could be argued that this increasingly aggressive stance taken by staff has come about as a result of a decline in normative integration and commitment following an erosion of the traditional employment relationship, and in the light of perceived threats to the number or quality of jobs in the industry. Without ruling out this possibility entirely, it must be said that there is little evidence to support such a claim. For example, there has never been any suggestion that the new systems be opposed altogether. On the contrary the union has recognised the need for the industry to adopt new technology in the interests of efficiency and maintaining competitiveness. NZBOU officials would argue that the banning policy was adopted only as a result of the banks' refusal to acknowledge additional demands and to enter into negotiations.

Equally it could be said that the collective response to date has been almost totally inneffectual, there being scant evidence of the banks having to alter their plans as a result of staff opposition. On the other hand, the experience of the last few years has shown unquestionably that a major change has occurred in the climate of industrial relations. Before computerisation there had been a history of relative calm and harmony, during which there were few signs of a willingness to adopt tactics which are more typical of industrial relations in the manufacturing sector. The possibility of a collective challenge to traditional management prerogatives would have been unthinkable before 1968. Today the climate of industrial relations is such that a major confrontation in the near future cannot be ruled out. The dispute which occurred in September of this year - arguably more to do with setting the ground rules for the future introduction of new technology than with branch opening hours - lends support to this view. In some respects the changes which computerisation has brought to the industry have significantly increased the liklihood of conflict. For example, the traditional policies of a broad recruitment base, promotions from within, and relatively permeable hierarchies, meant that management could introduce new systems without having to confront problems of job demarcation. And the grading system based upon length of service minimised the possibility of new systems upsetting skill differentials. Today both issues are a potential source of dispute.

Undoubtedly centralisation has also increased the power base of some staff. For example, the concentration of processing work at the site of the computer, creates the conditions under which staff may effectively disrupt banking operations should they so decide. To date this weapon has not been used to any great extent, but if in the future there is a sharpening of differences between the banks and their staff over the introduction of new technology, the possibility of it being brought to the bargaining table cannot be ruled out.

\section{Conclusion}

Inevitably much of the preceding analysis has been tentative and somewhat imprecise. Nevertheless it is worthwhile to offer a number of general conclusions.

Firstly, there is little evidence to support the contention that computerised banking offers workers an "emerging utopia" in which they can exercise control and experience social integration in the workplace. However, a crude deskilling thesis is equally untenable. The "craft" status of traditional banking at sub-managerial levels is questionable, and there has not been a straightforward loss of control along each of the 4 dimensions discussed.

Nevertheless, the main thrust of the paper has been to argue that in spite of a concession of control to a small number of experts the new systems have served to extend management control. This has been achieved firstly by the redistribution of functions amongst a new stratum of easily replaced low control workers. The fact that most of these workers were women lends support to the view that the initial feminsation of the industry was a consequence of mechanisation. The continued existence of a 2 -tier structure of employment suggests that computerisation has not reversed this trend. Secondly, management control has been extended by the centralisation of functions. And thirdly, it has 
been extended by the development of a computer based bureaucratic rationality which enhances existing constraints imposed by written documents and the authority of senior staff by further reducing staff discretion and limiting their decision making functions.

The new systems have also changed the shape of the employment relationship for male clerks. On the face of it this implies a weakening of management control through this mechanism. To some extent this is perfectly true. No longer can the banks create a system of dependence based upon career opportunities alone. However, the fear of unemployment coupled with limited alternative employment opportunities ought to maintain a relationship of dependency in the immediate future.

Finally, on the question of employee response, it is difficult to imagine that the interests of staff and the banks will not collide in the future. Unless the tremendous increase in the range of services provided by the banks in the 1970 s continues indefinitely, and this is most unlikely, it is self evident that aggregate employment will decline as the immense labour saving potential of the electronic funds transfer system is realised. Immediately affected would be those in the lower grades which currently provide the bulk of female employment in the industry. If so, women's traditionally higher rates of natural attrition might encourage the banks to adopt sinking lid policies which could be acceptable to existing staff. Accordingly a more likely source of opposition might be those employed in the higher grades who face either a reduction in levels of control or career prospects, or - given the heavy weighting which the current grading system attaches to supervisory responsibilities - face the prospects of having their positions downgraded.

\section{References}

All Union Conference on Technology (1981) The impact of new technology in the finance industry.

Bank of New Zealand (various issues) Annual reports Wellington.

Blauner, R (1964) Alienation and freedom London, University of Chicago Press.

Braverman, H. (1974) Labor and monopoly capital New York, Monthly Review Press.

Chappell, N M (1961) New Zealand bankers hundred Wellington, Bank of New Zealand.

Chequemate (various issues) New Zealand bank officers indusirial union of workers Wellington.

Crompton R (1979) Trade unionism and the insurance clerk Sociology 13(3) : 403-422.

Databank Systems Limited (1982) Report to staff Wellington

Dawe, C S (1980) Banking and technology Winter conference of the New Zealand association of economists Wellington

Friedmann, G (1961) The anatomy of work London, Heinemann.

Fox, A (1974) Beyond contract: work, power and trust relations London, Faber and Faber.

Game, A and Pringle, R (1983) Gender at work Sydney, Allen and Unwin.

Goulter, P and McCall, J (1981) New systems in banking - a union approach The annual conference of the sociological association of Australia and New Zealand Christchurch.

Hogg, G H J (1981) Payment systems developments in New Zealand Journal of bank research Winter 1981:219-222

Kumar, K (1978) Prophecy and progress - the sociology of industrial and post-industrial society Harmondsworth, Penguin.

Littler, C R (1982) The development of the labour process in capitalist societies London, Heinemann. 
Moore, B A and Barton, J S (1935) Banking in New Zealand Wellington New Zealand Bank Officers Guild.

New Zealand Bank Officers Union Report for Members (1981) The skills exercise - our case Wellington, NZBOU.

Pilling, J (1982) Computerised banking Chequemate March $1982: 2$

Stickler, J C (1949) The human element in the banking machine The New Zealand banker $15(10): 24-31$. 